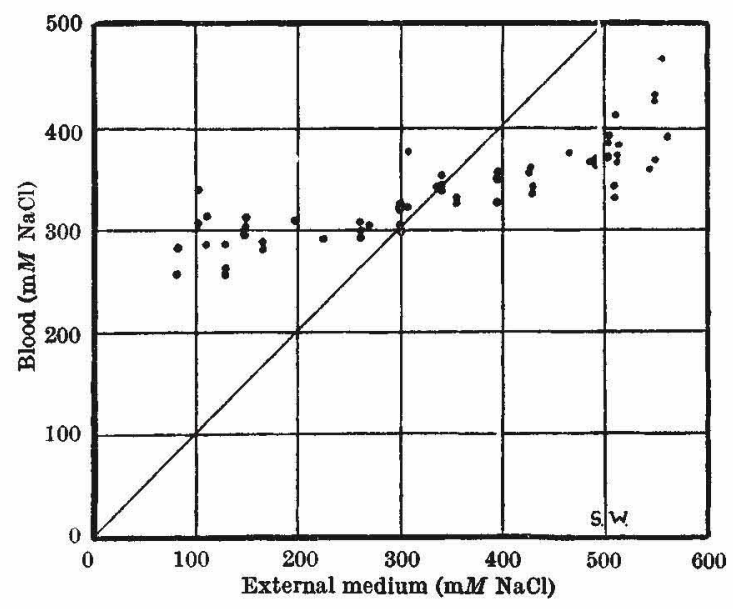

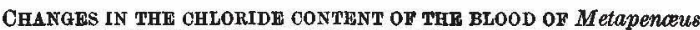
MONoceros IN DIFFERENT CONCENTRATIONS OF THE RXTERNAL MEDIUM

Diagonal line indicates where points would fall if the chloride concentration for external and internal media were identical Each point represents mean values obtained for estimations
carried out on a single specimen. $S . W$, range of undiluted sea water

we have recently examined the changes in the chloride content of blood in this prawn by employing the micro-modification of the Volhard titration as de. scribed by Wigglesworth ${ }^{3}$. The results obtained appear to be of considerable interest since powers of active regulation of ohloride are developed to a very high degree in this prawn (see graph).

The amount of chloride in blood is in the neighbour. hood of $\mathbf{2 \cdot 2}$ per cent sodium chloride as against 2.9-3.0 per cent for the external sea water, showing a definite tendency on the part of the animal to resist the uptake of chloride. An average of twelve estimation in animals kept under identical conditions in sea water gives chloride values of $2 \cdot 16$ per cent sodium chloride $(370 \mathrm{mM}$.) for blood as against 2.92 per cent (500 $\mathrm{m} M$.) for the external medium. An external salinity equivalent to $1 \cdot 9-1 \cdot 8$ per cent sodium chloride (20 per mille) gives approximately similar values for blood and the external medium, but in media of still lower salinities the animal is able to maintain a fairly steady chloride concentration; and even in the lowest salinity of 5-6 parts per mille to which the species has been acclimatized in experimental tanks, there is no fall in chloride concentration below about $250 \mathrm{mM}$. These values in low dilutions of sea water are very much higher than in many other euryhaline animals on which studies have been made. On the other hand, chloride values for prawns kept in sea water are appreciably lower than for most marine invertebrates ${ }^{4,5}$. A general

\section{Active Regulation of Chloride in Metapenzeus monoceros Fabricius}

Metapenous monoceros is a widely distributed Indo-Pacific prawn often met with in shores and estuaries liable to great variations in salinity. At Madras, it is a common inhabitant of the saline part of the Adyar and Cooum Rivers, and sexually mature as well as post-larval prawns have been obtained in brackish water ${ }^{1}$. Dakin ${ }^{2}$ has recently reported that the Australian species of Metapenceus, which is usually known under the name $M$. monoceros but is believed to be different, breeds in the coastal lakes and estuaries unlike other Penæids. As part of a programme of study on the osmotic regulation in Penæid prawns, similarity between this species and the Chinese woolhanded crab (Eriocheir sinensis) ${ }^{6}$ may, however, be found.

The significance of these results lies in the fact that the Penæid prawns show in their osmotic properties a condition probably similar to that described for the Palæmonid prawns? ${ }^{7}$ both in their ability to maintain a hypotonic blood in defiance of the external medium and the homoi-osmotic behaviour as judged by the fairly steady values for chloride over a wide range of dilutions of the external medium. From these observations on Metapenceus it also seems probable that the hypotonic osmo-regulation in the few instances described 7,8 , which is presumably of much wider occurrence than is at present realized, is 
achieved as a result of the active regulation of the chloride ion by these crustaceans.

Further experiments are in progress and will be fully reported elsewhere.

doi:10.1038/161137a0

N. Kesava Panikgar

R. VISWANATHAN

Central Marine Fisheries Station,

Triplicane P.O, Madras.

Sept. 25. ' Panikkar, N. K., and Aiyar, R. G., Proc. Indian Acad. Sci, B, 9,
$\mathbf{3 4 3}$ (1939).

${ }^{2}$ Dakin, W. J., Nature, 158, 99 (1946).

Wigglesworth, V. B., Biochem. J., 31, 719 (1938).

"Krogh, A., "Osmotic Regulation in Aquatic Animals" (Cambridge Univ. Press, 1939).

5 Beadle, I. C., and Cragg, J. B., J. Exp. Biol., 17, 437 (1940).

- Scholles, W., Z. vergl. Physiol., 19, 522 (1933)

'Panikkar, N. K., J. Mar. Biol. Assoc. 25, 317 (1941).

- Brockema, M. M., Thesis, Groningen (19+1). 